\title{
Qualitative Content Analysis of Forest Healing Experience in Forest Life
}

\author{
Hee Won Kang ${ }^{1}$ and Geo Lyong Lee ${ }^{2 *}$ \\ ${ }^{1}$ Doctoral student, Department of Integrative Medicine, Graduate school of Sun Moon University, Asan 31460, Korea \\ ${ }^{2}$ Associate professor, Department of Integrative Medicine, Graduate school of Sun Moon University, Asan 31460, Korea
}

\section{ABSTRACT}

Background and objective: The purpose of this study is to analyze the case of healing experience for lifestyle and environmental diseases through life and activities in the forest from the perspecitive of critical realism, and how the causal power and mechanism of the healing experience relate to forest healing factors and programs.

Methods: 93 video data of people who started living in the forest for disease treatment were analyzed using a qualitative content analysis method from the perspective of critical realism. Categories for analysis include general categories (age, duration, occupation, disease name), forest therapy categories (climate therapy, plant therapy, water therapy, diet therapy, kinesiotherapy, psychotherapy), and other categories (ecology, learning and management, life tools), etc., and the unit of analysis is the context unit.

Results: 1) The diseases that motivated life in the forest were digestive system diseases, lung diseases, cardiovascular diseases, endocrine system diseases, and various lifestyle-related diseases and environmental diseases in similar proportions. This indicates that forest life does not have specificity to respond to specific diseases, but provides treatment and recovery for all lifestyle and environmental diseases.

2) Among the forest therapies, climate therapy and plant therapy are related to the climatic and residential environment in the forest where 'natural persons' live. And others such as water therapy, diet therapy, kinesiotherapy, psychotherapy indicate the change from the lifestyle that caused the disease to the lifestyle for treatment and recovery.

Conclusion: Life and activities in the forest provide an environment for treatment and recovery in which the healing principles such as aromatherapy, nutritional and dietary therapy, kinesiotherapy, and emotional psychotherapy are integrated in the 'real world'.

Keywords: natural persons, lifestyle diseases, environmental diseases, ecology, critical realism

\section{Introduction}

Recently, many people are visiting forests regularly for hiking, trekking, camping, recreation forests, healing forests, and temple stay on a regular basis, or planning to live a nature-friendly life by moving to rural areas. Some are even living full-time in the forests as a 'natural person' (a term used in Korea to refer to people living in the wild). Increasing discussions and public interest in forest therapy as a method of natural healing is also due to the popularized reflective awareness of lifestyle and environmental diseases. In other words, healing factors and programs presented by forest therapy improve the improper lifestyles and environments of people today that cause diseases, thereby preventing and treating the diseases from the perspective of natural healing (Yoo et al., 2015).

The features of forests that promote health and treat diseases are recently perceived scientifically and receiving full

This paper was based on the revision of the master's thesis.

Received: April 16, 2021, Revised: May 21, 2021, Accepted: May 25, 2021

First author: Hee Won Kang, howkang@nate.com, (1) https://orcid.org/0000-0002-4704-1534

*Corresponding author: Geo Lyong Lee, leeashram@hanmail.net, (1) https://orcid.org/0000-0003-2786-7563 
attention since there was a study published on the fact that conditions where one can see the natural environment have a positive effect on the recovery of patients that received gallbladder surgery (Ulrich, 1984). Moreover, as a result of showing 120 videos on natural and urban environments and measuring stress recovery, it was found that there was a healing effect just by being in the natural environment (Ulrich et al., 1991). Furthermore, other related studies are proving the physiological effects of forest therapy, such as decrease in stress caused by the declining cortisol levels (Tryvainen et al., 2014) and increase in immunity due to activation of $\mathrm{NK}$ cells (Li, 2010) and the psychological effects of forest therapy such as decrease of negative emotions (Morita et al., 2007) and promotion of happiness (Mackerron and Mourato, 2013).

There are also active studies on forest therapy in Korea that cover the physiological, psychological, and social effects on all ages from children to the elderly as well as various disease groups (Oh, 2017), but most are positivist quantitative studies with one-time and short-term measurements (Sung et al., 2015). These quantitative studies merely list the regularity of experiences but fail to determine the mechanism and correlation of physiological, psychological, and social healing of individual patients with certain diseases with forest therapy factors and therapies.

Accordingly, this study will analyze the forest life and activities of natural persons that fully display the natural healing character of forest therapy based on critical realism and explain the healing mechanism and structure using the forest therapy theory. Therefore, the objective of this study is to analyze the media cases of the life of natural persons from the perspective of critical realism and determine the forest therapy experience (empirical domain) in forest life of natural persons, the common grounds in lifestyles of natural persons and forest therapy (actual domain), and the principles of internalizing forest therapy factors in forest life of natural persons(real domain).

\section{Research Methods}

\section{Critical realism and qualitative content analysis}

This study uses the method of qualitative content analy- sis from the perspective of critical realism and analyzes forest therapy experiences in media cases that deal with the lives of natural persons living in the woods.

Qualitative research from the perspective of critical realism is methodologically conducted on specific cases or subjects, but since it explores the causality of phenomena with focus on in-depth structure and mechanism (Lee, 2006), it seems like an adequate perspective for analyzing the experiences and meaning of forest therapy in the forest life of natural persons. Moreover, qualitative content analysis is a research method that systematically and objectively describes and quantifies the phenomenon, as well as a qualitative analysis used to systematically analyze the meanings revealed in media materials. In qualitative content analysis, directive content analysis is a method that deductively analyzes existing theories to validate and expand their concept (Son, 2017). Therefore, it is a useful method to analyze the forest therapy experiences and meaning in forest life of natural persons with the categories of forest therapy factors and programs presented in relevant theories.

\section{Procedures}

This study analyzed the data using a deductive approach according to the content analysis procedures of PreparationOrganizing-Reporting by Elo and Kyngäs (2008) as shown in Table 1.

\section{Subjects}

The subjects of analysis are cases of forest life in MBN's documentary program 'I Am a Natural Person'. It premiered in August 2012 and has aired 445 episodes so far as of the end of March 2021, but this study analyzed up to Episode 432 aired on December 30, 2020 when the data analysis began. The types of data were 432 episodes of replay VOD service, 432 text previews, over 2,500 posts by viewers, 2 books titled [I Am a Natural Person] published by the production team, and other website and online materials. First, we analyzed the text previews and posts by viewers, after which we selected 93 VOD episodes of natural persons that started forest life motivated by treatment of diseases according to the research objective to analyze the experience and meaning of forest therapy in forest life. 
Table 1. Content analysis process

\begin{tabular}{|c|c|c|}
\hline $\begin{array}{l}\text { Preparation } \\
\text { Phase }\end{array}$ & $\begin{array}{l}\text { - Selecting the unit of analysis } \\
\text { - Understanding of data and } \\
\text { context }\end{array}$ & $\begin{array}{l}\text { First analysis of } 432 \text { broadcast information, } 2,500 \text { viewer posts, } 2 \text { books of [I am a } \\
\text { natural person], homepage and Internet data }\end{array}$ \\
\hline $\begin{array}{l}\text { Organising } \\
\text { Phase }\end{array}$ & $\begin{array}{l}\text { - Structured Analysis Mattress } \\
\text { Development } \\
\text { - Data coding according to } \\
\text { categories } \\
\text { - Hypothesis verification } \\
\text { - Comparison with existing studies }\end{array}$ & $\begin{array}{l}\text { Selecting-Based on the results of the first analysis, } 93 \text { VODs of natural persons who } \\
\text { started living in the forest for the purpose of disease healing were selected. } \\
\text { Categorization-Determination of analysis categories and context units based on } \\
\text { consideration of the theoretical background related to forest life and forest healing } \\
\text { Analysis-Secondary analysis of } 93 \text { VODs according to categories such as climate } \\
\text { therapy, plant therapy, water therapy, diet, exercise therapy, psychotherapy, ecology, } \\
\text { etc. }\end{array}$ \\
\hline $\begin{array}{l}\text { Reporting } \\
\text { Phase }\end{array}$ & $\begin{array}{l}\text { - Model } \\
\text { - Concept system } \\
\text { - Concept map }\end{array}$ & $\begin{array}{l}\text { Based on the analysis results, verification of research problems and comparison with } \\
\text { existing studies are performed. }\end{array}$ \\
\hline
\end{tabular}

\section{Classification}

To analyze forest therapy experiences in forest life of natural persons, we classified forest therapy factors and programs by category.

Forest therapy factors are classified into six categories: visual, auditory, olfactory, gustatory, tactile, and conscious elements. Forest therapy programs are classified into the six major forest therapy programs presented by Korea Forest Service, such as plant therapy, water therapy, diet therapy, kinesiotherapy, climate therapy, and psychotherapy (Korea Forest Service, 2011). In the actual data analysis process, the six forest therapy programs were used as the categories, and forest therapy factors were used as the context unit of related programs.

\section{Unit and aggregate}

The unit of analysis is context unit. Context unit is the maximum unit of contents intended for clearer review in the record unit, and it is used in consideration of the whole context when it is difficult to clearly analyze with just record unit (Choi et al., 2016b). When there was a context unit relevant to the content analysis table while watching the VOD, this was used as the unit of analysis and included in the category. The aggregate of this study is based on appearance. When there was anything relevant to forest therapy related to forest therapy factors in the life and activities of natural persons in the VOD, we recorded it in the content analysis table as shown in Fig. 1 and analyzed it.

\section{Reliability and validity of research}

Elo et al. (2014), who presented the procedures of qualitative content analysis such as Preparation-OrganizingReporting, provided a checklist for researchers to increase the reliability of research in each phase. According to this checklist, the Preparation phase must validate the researcher's data collection ability and method, data saturation and sample adequacy. The Organizing phase must validate categorization and abstraction, data interpretation, and data representativeness. The Reporting phase must validate the systematicity and logicality of descriptions, concept and content structure, and use of scientific terminology.

To increase reliability and validity of this study, we checked and assessed the required matters in each phase according to the checklist and tried to understand the context, maintain sensitivity to the category content and data, and improve systematicity and logicality. Finally, to overcome the limitations of qualitative content analysis in content validity, we sent a questionnaire on ethicality, reliability, and validity to the production team of MBN' I Am a Natural Person'that are the creators of this work, and requested minimum fact check.

\section{Results and Discussion}

\section{Analysis results according to general categories}

The results of analyzing the general matters including 


\begin{tabular}{|c|c|c|c|c|c|c|c|c|c|c|c|}
\hline No. $\mathrm{F}$ & Perio & Age & Occupation & Disease & Climate therapy & Plant therapy & Water therapy & Diet therapy & Kinesiotherapy & Psychotherapy & Ecologism \\
\hline 1 & 8 & 54 & Bit part actor & Vision loss, & Deep in the & Mugwort scent, & Valley water & Vegetable garden, & Morning exercise, & Candle meditation & Only nature gives \\
\hline 2 & 15 & 59 & Conglomerate - & Late stage renal & Valley & Relocated Jeonju & Cold-water & Vegetable garden, & Bowing exercise, & Listening to music & Care leads to \\
\hline 3 & 13 & 69 & Garak Market & Renal cancer - & 500 above sea & Rented a deserted & & Vegetable garden, & Herbal hike, pine & Journal writing & The ideal spot is \\
\hline 4 & 43 & 67 & Engineering & Late stage gastric & Penniless, & Log cabin, & Cold bath & Wild edible & Herbal hike, five & 1000-day & I'm grateful for the \\
\hline 5 & 10 & 59 & Bus, fish boat & Falling, & Penniless, & Round hut & Mugwort bath & Vegetable garden, & Herbal hike, rehab & Forest meditation & I'm brought back \\
\hline 6 & 5 & 63 & Video wholesaler & Gallbladder & 700 above sea & Mud house & & Water celery & Hiking, dancing, & & Natural healing, \\
\hline 7 & 10 & 55 & Livestock industry & Lung disease such & Penniless, 500 & Landscape & Steam massage, & \begin{tabular}{|l|} 
Vegetable garden, \\
\end{tabular} & Herbal hike, & Praying in front of & Life of non- \\
\hline 8 & 34 & 61 & Construction & Falling, porosis - & Penniless, across & Panel house made & & Vegetable garden, & Hiking, & Mountain spirit & Assimilation into \\
\hline 9 & 11 & 64 & Construction & Hepatic cirrhosis, & & Tent-vinyl & Cold bath - instead & Vegetable garden, & Hiking, morning & Yoga, scared & To live in the \\
\hline 10 & 18 & 74 & Clothing factory - & Peritonitis - & Penniless, solitary & House made of & & Vegetable garden, & Cleaning, & Lake meditation, & Nature must be \\
\hline 11 & 5 & 56 & Jewelry factory, & Ulcerative colitis & Valley, hometown, & Old mud house, & & Vegetable garden, & Hiking, dance & Landscape & Nature is a side \\
\hline 12 & 24 & 75 & Army contractor & Stage 4 thymic & valley & Hut made of waste & Mugwort bath & Medicinal herb & Hiking, forest & Valley meditation, & Picking up trash \\
\hline 13 & 14 & 66 & Bus, taxi - stress & Lung cancer, knee & 500 above sea & House & & Vegetable garden, & Hiking, bamboo & Happy feeling, my & Emptying the mind, \\
\hline 14 & 5 & 56 & Karaoke business & Stage 2 bladder & next to a valley & US army bus & & Vegetable garden, & Hiking & Conversation with & Assimilated into \\
\hline 15 & 25 & 66 & Patrol - day and & Late stage & next to a valley & Container, biwak & & Fermented liquor, & Hiking every day, & Giving to others & To die in peace \\
\hline 77 . & 4 & 67 & Miner, tunnel const & Accident- parapare & next to a valley & Remodeled containd & Mugwort bath & Shiitake, native hon & Herbal hike, barefo & Love for family & \\
\hline 78 & 6 & 58 & Craftsmanship - re & Cerebral haemorr & Seashore & Remodeled containe & & Fish, pork skin & Herbal hike & & \\
\hline 79 & 15 & 59 & Food material busin & Alcoholic liver dise & Penniless, 900 abor & \begin{tabular}{|l|} 
Red clay wood \\
\end{tabular} & & Marsh snail, wild ed & Herbal hike & & \\
\hline 80 & 5 & 68 & Recycling company & Rectal cancer & Penniless, 900 abo & \multicolumn{2}{|c|}{ Vinyl greenhouse red clay room } & Ginseng field, thistt & \multicolumn{2}{|l|}{ Herbal hike, sandbag } & Self-sufficient \\
\hline 81 & 5 & 64 & Occupation solider- & \multicolumn{2}{|c|}{ Diabetes complications } & \multicolumn{2}{|c|}{ Vinyl greenhouse container } & Lycium, snail & \multicolumn{2}{|l|}{ Herbal hike, sandbag } & \\
\hline 82 & 5 & 66 & Police officer & Cerebral infarctic & Penniless, $1000 \mathrm{abd}$ & Panel home & & & \multicolumn{2}{|l|}{ Herbal hike, exercise } & Satisfied \\
\hline 83 & 7 & 63 & Fiber manufacturins & Gastric cancer & Penniless, $600 \mathrm{abo}$ & Panel home & & Freshwater shrimp, & Herbal hike, kung $\mathrm{f}$ & \multicolumn{2}{|c|}{ Divorce/love for child } \\
\hline 84 & 9 & 71 & Taxi driver & Renal cancer & 600 above sea leve & \multicolumn{2}{|c|}{ Red clay brick hous Foot bath } & Clavaria, turmeric & Barefoot hiking & \multicolumn{2}{|c|}{\begin{tabular}{|l|l|} 
Love for family, no Satisfied \\
\end{tabular}} \\
\hline 85 & 10 & 58 & Nurse & Thyroid cancer, ma & 800 above sea leve & Remodeled vinyl gre & eenhouse & Organic tofu, sumad & Hiking & \multicolumn{2}{|c|}{ Divorced, daughter, I'm great } \\
\hline 86 & 7 & 65 & Carpenter, construd & Stage 3 colorectal & Family gravesite, $s$ & \multicolumn{2}{|l|}{ Remodeled container } & Fish rice porridge, $\mathrm{n}$ & mushroom water, sh & Love for family & \\
\hline 87. & 7 & 68 & Dry cleaner's - cha & Pneumonia - moved & slash-and-burn far & Remodeled contain & Mugwort foot bath & Indian potato, ballo & \multicolumn{2}{|l|}{ Sandbag, herbal hike } & \\
\hline 88 & 18 & 70 & Boiler facilitics & Cardiac infarction & Family gravcsitc, b & \begin{tabular}{|l|} 
Pancl home \\
\end{tabular} & \begin{tabular}{|l} 
Mugwort bath \\
\end{tabular} & Garlic, yam powder & Excrcisc, hiking & \multicolumn{2}{|c|}{ Cometery managomont, family's health } \\
\hline 89. & 11 & 64 & Construction & Hyperthyroidism - & hometown, next to & Log cabin & & Elm bark, tara vine & Pulley exercise & Love for family & Ash soap \\
\hline 90 & 9 & 62 & Panel processing br & Parkinson's disease & Penniless, hometow & Panel home & & & Hiking at night & \multicolumn{2}{|c|}{ Loneliness, love for family } \\
\hline 91] & 3 & 64 & Raw fish restaurant & Pancreatic cancer, & \multicolumn{3}{|c|}{ riverside, hometown, vinyl greenhouse, container } & Angelica, evening $\mathrm{a}$ & Herbal hike & & \\
\hline 92 & 6 & 58 & Factory worker, ler & Panic disorder & 500 above sea leve & Remodeled contain & Winged euonymus & Gromwell, goatsbed & Bar exercise, hikin & Satisfied & \\
\hline 93 & 6 & 60 & Landscaping servic & troke & Lakeside, hometow: & & & Shiitake, supplejack & root & & \\
\hline
\end{tabular}

Fig. 1. Content analysis table compression example.

Table 2. General category analysis summary (Unit-person)

\begin{tabular}{|c|c|c|c|c|c|c|c|c|c|}
\hline Age & \multicolumn{2}{|l|}{$20 \mathrm{~s}$} & $30 \mathrm{~s}$ & $40 \mathrm{~s}$ & \multicolumn{2}{|c|}{$50 \mathrm{~s}$} & $60 \mathrm{~s}$ & $70 \mathrm{~s}$ & Average \\
\hline Current age & \multicolumn{2}{|l|}{-} & - & 1 & \multicolumn{2}{|c|}{35} & 48 & 9 & 62 years \\
\hline Starting age & \multicolumn{2}{|l|}{2} & 3 & 22 & \multicolumn{2}{|c|}{51} & 15 & - & 52.3years \\
\hline \multirow{2}{*}{ Period } & \multicolumn{3}{|c|}{ Under 10years } & \multicolumn{3}{|c|}{ 10-19years } & \multicolumn{2}{|c|}{ Over 20years } & Average \\
\hline & \multicolumn{3}{|c|}{54} & \multicolumn{2}{|c|}{33} & \multicolumn{3}{|c|}{6} & 9.8years \\
\hline \multirow{2}{*}{ Career } & \multirow{2}{*}{\multicolumn{2}{|c|}{$\begin{array}{l}\text { Self Employed } \\
57\end{array}$}} & \multirow{2}{*}{$\begin{array}{c}\text { Field labor } \\
13\end{array}$} & \multirow{2}{*}{\multicolumn{2}{|c|}{$\begin{array}{c}\text { Driver } \\
12\end{array}$}} & \multirow{2}{*}{$\begin{array}{c}\text { Office worker } \\
9\end{array}$} & \multirow{2}{*}{\multicolumn{2}{|c|}{$\begin{array}{c}\text { Others } \\
2\end{array}$}} & \multirow[t]{2}{*}{ Remarks } \\
\hline & & & & & & & & & \\
\hline \multirow[t]{2}{*}{ Sickness } & Diges-tive & $\begin{array}{l}\text { Cardio- } \\
\text { vascular }\end{array}$ & Lung & $\begin{array}{l}\text { Musculo- } \\
\text { skeletal }\end{array}$ & Liver & Endocrine & Mental & Urinary & Remarks \\
\hline & 17 & 14 & 12 & 12 & 11 & 11 & 8 & 5 & 3 \\
\hline
\end{tabular}

age, forest life period, occupation before forest life, and disease that motivated forest life are as shown in Table 2.

\section{Forest therapy experience in forest life}

Natural persons that experienced treatment of disease in forest life all say that 'the mountains saved me'. They are certain that the forest and nature cure illnesses. They did not give up on forest life even after they were cured and resolved not to return to the city. The forest therapy experience in the forest life of natural persons is explained as follows, and this is the 'empirical domain', a set of people's 
experiences on events mentioned in critical realism.

First, there were various diseases that motivated natural persons to live in the forest: digestive disorders such as colorectal cancer, colitis, gastric cancer, rectal cancer, etc.; cardiovascular diseases such as cardiac infarction, valvular disease of the heart, angina, cerebral infarction, hypertension, orthostatic hypotension, etc.; lung diseases such as lung cancer, pneumoconiosis, pneumothorax, asthma, COPD, etc.; musculoskeletal system disorders such as aftereffects of falls and traffic accidents and lumbar disc, etc.; liver diseases such as liver cancer, hepatic cirrhosis, gallbladder cancer, biliary tract cancer, etc.; endocrine disorders such as diabetes, thymic carcinoma, pancreatitis, etc.; mental illnesses such as depression, panic disorder, etc.; urinary disorders such as renal failure, renal cancer, bladder cancer, prostate cancer, etc.; and other illnesses such as brain tumor, vision loss, etc. There were 27 natural persons diagnosed with cancer such as gastric cancer, colorectal cancer, and lung cancer and received surgery or anticancer therapy. This indicates that forest life does not have the specificity to respond to specific diseases but provides treatment and recovery for all lifestyle and environmental diseases.

Second, the autonomy in decision making that appeared in the occupational background of natural persons not only enabled them to decide to live in the forest but also played a positive role in treating their diseases. Most of the occupations they had before forest life required autonomous decision making, such as self-employed in construction, machinery, equipment, restaurant, manufacturing, and retail businesses, workers in construction sites, and bus and taxi drivers. The autonomous decision making of natural persons enabled them to have an active will and make their own treatment plan instead of uncritically accepting the doctor's diagnosis and prescription in a life-or-death situation with a critical illness. This is an important element in relation to the patient's attitude in coping with the disease.

Third, the complete freedom that natural persons feel in forest life is the start of their mental and psychological change as well as healing. Complete freedom is accompanied by severe loneliness, which leads to introspection. Introspection results in ecological thinking, making them commune with all living organisms in the forest including trees and flowers, which leads to gratitude toward all living things. This progresses into mental and psychological communion beyond physical and chemical communication and communion through the five senses such as the forest landscape, sounds, scents, taste, and touch, thereby starting natural healing that integrates the body and soul.

Fourth, in forest life, natural persons must handle everything necessary in life including food, clothing, and shelter on their own. All kinds of labor for self-sufficiency drive them to constantly think, learn, and move whenever necessary, helping them treat their illnesses. Humans are originally beings that develop their capabilities and fulfill themselves through labor. Through all kinds of labor that require them to commune with nature, natural persons are not only developing their physical and mental capabilities but also learning how to properly build relationships with all others and obtaining emotional stability and peace.

\section{Similarities of the lifestyle of natural persons and forest therapy}

Among the six forest therapies, climate therapy and plant therapy are related to the climatic and residential environment of the forests in which the natural persons are living, indicating a transition from the environment of disease to the environment of treatment and recovery. Other therapies such as water therapy, diet therapy, kinesiotherapy, and psychotherapy indicate the change from the lifestyle that caused the illness to the lifestyle for treatment and recovery. In other words, the similarities of forest therapy and the lifestyle of natural persons are in changing the lifestyle and environment that caused the illness to the lifestyle and environment for treatment and recovery. This is the 'actual domain', a set of events that are occurring regardless of people's experiences and will continue to occur in the future.

First, climate therapy is a program that uses the microclimate of the forest as a healing factor, such as sunbath, forest bath, wind bath, air bath, and cold air bath. Climate therapy in forest life of natural persons can be found in the climatic environment of where they live. The place where they live are mid-mountainous areas surrounded by 
forests in all four directions, and most have valleys nearby. Climate therapy is a routine for natural persons creating a microclimate by adjusting the temperature and humidity on their own and living in an ecological forest with high oxygen concentrations.

Second, plant therapy is a program that uses forest landscape or phytoncide from plants as healing factors, such as forest bath, aromatic bath, pressed flowers, plant crafts, plant observation, forestry operation, and native grass experience. Plant therapy in forest life of natural persons can be found in the environment of their residence and home. The outdoor activities of natural persons in the forest of a mid-mountainous area are in an environment where forest therapy factors are in full operation such as forest landscape and phytoncide. Their indoor life in eco-friendly homes they built with natural materials such as wood and clay are also an extension of forest bath and aromatic bath. In addition, finding firewood, taking herbal hikes, and tending gardens can also be included in plant therapy.

Third, water therapy is a program that uses water in the forest as a healing factor, such as Kneipp water therapy, cold and warm bath, foot bath, and hot spring bath. Water therapy in forest life of natural persons is a therapy used as a purpose, hoping for a therapeutic effect. Cold and warm baths (including lower-body bathing and cold-water rubbing) are used in various ways by putting in all kinds of medicinal herbs such as mugwort, pine needles, persimmon vinegar, sophora root, loquat, and winged euonymus.

Fourth, diet therapy is a program using medicinal food ingredients such as wild edible greens and medicinal herbs found in the forest as healing factors, such as wild herbs and vegetables, wild green fermented drinks, flower tea, fruits, sap, and forestry product processed foods. Diet therapy in forest life of natural persons includes tending gardens, finding wild edible greens and medicinal herbs in season, using fermented drink and herbal water, enjoying a healthy vegetarian diet, eating little, and a low-salt diet, and consuming high-quality nutrition such as shiitake and honey. In other words, food that natural persons eat on a daily basis in their forest life are oriental medicine food therapy from collecting or growing medicinal herbs approved by oriental medicine for treatment of diseases and mixing them organically with other food ingredients.
Fifth, kinesiotherapy is a program that uses the forest landscape and terrain as healing factors, such as terrain therapy, hiking, trekking, walking barefoot, forest bathing, tree climbing, and orienteering. Kinesiotherapy in forest life of natural persons is a therapy considered essential among all the natural persons. They all have their own exercising method by hiking every day to collect herbs and firewood and meditate. The daily house chores they must do to feed and house themselves naturally increase their physical activities, which also serve as an exercise.

Sixth, psychotherapy is a program that increases psychological stability and relieves stress by meditating in the forest, such as forest meditation, forest yoga, forest writing, forest art, forest music, and self-counseling. Psychotherapy in forest life of natural persons appears in various forms such as landscape meditation, valley meditation, candle meditation, dance meditation, yoga, journal writing, stone tower building, prayers in front of a sacred tree or stone tower, communion with a guardian tree or mountain spirit, and prayers for the family.

\section{The principle of internalizing forest therapy factors in the forest life of natural persons}

The perception on the 'empirical domain' of forest therapy experience in the forest life of natural persons and the 'actual domain' of the similarities with forest therapy has become clear. Then what is the set of mechanisms in the 'real domain' that brings therapeutic experiences to natural persons?

First, there is the principle of aromatherapy. Phytoncide is a volatile hydrocarbon compound $(\mathrm{CH})$ produced by plants that affects other living things made of similar carbon skeletons (CHONSP). The theories of aromatherapy have already proved the principles in which phytoncide affect the human body in various ways by being absorbed through the respiratory system and skin (Park et al., 2018). Forest life of natural persons is an environment where they can enjoy the pharmaceutical efficacy of the plant aroma substance without side effects. Moreover, the forest environment in mid-mountainous areas serves as an environment for treatment and recovery due to the oxygen concentrations and climate different from the city. 
Second, there is the principle of nutritional and dietary therapy. Our body is in dynamic equilibrium that changes constantly according to the lifestyle and environment, and is not fixed. The food we eat is not completely combusted into energy but remains in our body about $50 \%$. After a year, $98 \%$ of the elements of our body are replaced by other elements, indicating that the food we eat turn into a part of our body (Guggenheim, 1991). Natural persons are living in the forest for at least 4 years, and the average length is 10 years. During this period, the food they eat on a daily basis is oriental medicine food therapy from collecting or growing medicinal herbs approved by oriental medicine for treatment of diseases and mixing them organically with other food ingredients (Kim et al., 2019). The illness disappears in a year, replaced by a newly composed body with oriental medicine food therapy.

Third, there is the principle of kinesiotherapy. The typical exercise of natural persons is hiking, such as walking in the forest. Walking in the forest does not bring just a regular exercise effect. The slopes and curves in the woods improve balance and force the use of various muscles, thereby promoting balanced physical development. Natural persons in the forest hike on a daily basis to collect medicinal herbs and firewood or to meditate. Hiking in the forest is a comprehensive forest therapy program to meet and commune with all forest therapy factors, such as phytoncide, landscape, sounds, sunlight, and various living things (Choi et al., 2016a).

Fourth, there is the principle of emotional therapy. The existential concerns experienced by facing death with a serious illness, the complete freedom felt in solitary forest life, introspection accompanied by severe solitude, and stability and peace from all kinds of labor in communing with nature are all emotional and psychological changes experienced by natural persons. These changes lead to ecological thinking such as the reciprocal and communal relationship with nature, respect for all living things and coexistence, minimum consumption, and non-possession. By developing into emotional and psychological communion beyond physical and chemical communication with forest therapy factors through the five senses such as forest landscape, sounds, scents, taste, and touch, actual healing that integrates the body and soul begins (Shin et al., 2015).

\section{Conclusion}

Forest therapy factors are various natural and environmental elements in the forest that affect the human body and mind, increase immunity, and promote mental and physical health, referring to forest plants and animals, landscapes, sounds, scents, water, light, climate, and terrain. The objective of this study is to explore how these factors are internalized in the healing experience of natural persons and how they serve as the causal power and mechanism of healing.

According to critical realism, the objective existence is structured into three dimensions: 'empirical domain' that is the set of experiences of people related to events, 'actual domain' that is the set of events that are occurring regardless of people's experience and will also occur in the future, and 'real domain' that is the set of mechanisms that define such events. The healing experience of natural persons is the 'empirical domain' that is the set of experiences related to events. This experience is also the 'actual domain' that is the set of events that can occur non-specifically to everyone in a forest life in the ecological sense instead of a certain disease or person. And the 'real domain' that is the set of mechanisms defining these events is the domain where forest therapy factors affect the human body and mind and induce the healing experience.

As one natural person said, 'being treated in the mountain is not a miracle but the order of nature,' forest therapy is not just an individual's experience. The principles of aromatherapy, nutritional and dietary therapy, kinesiotherapy, and emotional therapy are all operating synthetically in the 'real domain', inducing the healing experience. In other words, life and activities in the forest are providing an environment for treatment and recovery with an integrated effect of these principles.

This study determines the principles of forest therapy in the real domain with qualitative content analysis from the perspective of critical realism, but has the following limitations.

First, it is difficult to secure actual content validity because it is based on analysis of media materials. The TV program is filmed and edited according to the production team's intentions and needs, and thus it may not have fully 
reflected the forest life of natural persons. This is the common limitation of all studies using the qualitative content analysis.

Second, this study depends only on recorded data. All the data analyzed are limited to cases that succeeded in treating the disease through forest life. This does not identify cases of forest life that failed to be treated and recovered. It is also necessary to consider that forest environment may be a space for another illness or anxiety such as infection from toxic plants, poisonous insects, and bacteria.

Third, the healing experience of natural persons is not completely by the forest therapy factors. Most natural persons chose to live in the forest to manage their aftereffects and prevent relapse after receiving treatment in modern medicine such as surgery or anticancer therapy, and very few of them refused to receive surgery or anticancer therapy altogether.

\section{References}

Choi, J.H., K.H. Ryu, T.S. Kim, C.S. Shin, P.S. Yeon, and H.J. Kim. 2016a. Effects of 12-week forest exercise on blood lipids, SOD, and melatonin in the middle-aged women. J. Korean Inst. For. Recreat. 20(4):81-90. https:// doi.org/10.34272/forest.2016.20.4.008

Choi, S.H., J.H. Jung, and S.W. Jung. 2016b. Concept and procedures of qualitative content analysis. J. Qual. Inq. 2(1):127-155.

Elo, S. and H. Kyngäs. 2008. The qualitative content analysis process. J. Adv. Nurs. 62(1):107-115. https://doi.org/10.1111/j.1365-2648.2007.04569.x

Elo, S., M. Käärïäinen, O. Kanste, T. Pölkki, K. Utriainen, and H. Kyngäs. 2014. Qualitative content analysis: A focus on trustworthiness. SAGE Open. 4(2):1-10. https:// doi.org/10.1177/2158244014522633

Guggenheim, K.Y. 1991. Rudolf Schoenheimer and the concept of the dynamic state of body constituents. J. Nutr, 121(11):1701-1704. https://doi.org/10.1093/jn/121. 11.1701

Kim, Y.H., D.W. Joung, and B.J. Park. 2019. A study on analyze contents of forest based therapeutic programs in korea. J. Korean Inst. For. Recreat. 23(1):43-58. https://doi.org/10.34272/forest.2019.23.1.005
Korea Forest Service. 2011. Development of therapeutic program on forests(Report No. 11-1400000-000503-01). Daejeon, Korea: Author. Retrieved from https://www. forest.go.kr

Lee, Y.C. 2006. A theoretical status of a case study method in the social sciences research. Korean Public Adm. Rev. 40(1):71-90.

Li, Q. 2010. The trends on the research of forest bathing in japan, korean and in the world effect of forest bathing trips on human immune function. Environ. Health Prev. Med. 15(1):9-17. https://doi.org/10.1007/s12199-008-0068-3

MacKerron, G. and S. Mourato. 2013. Happiness is greater in natural environments. Glob. Environ. Change. 23(5): 992-1000. https://doi.org/10.1016/j.gloenvcha.2013.03.010

Morita, E., S. Fukada, J. Nagana, N. Hamajima, H. Yamamoto, Y. Iwai, T. Nakashima, H. Ohira, and T. Shirakwa. 2007. Psychological effects of forest environments on healthy adults: Shinrin-yoku(Forest-air Bathing, Walking) as possible method of stress reduction. Public Health. 121(1):54-63. https://doi.org/10.1016/j.puhe.2006. 05.024

Oh, K.H. 2017. Analysis of the forest therapy phenomenon based on the grounded theory. Doctoral dissertation, Chungbuk National University, Cheungju, Korea.

Park, J.H., S.H. Park, H.J. Lee, J.W. Kang, K.M. Lee, and P.S. Yeon. 2018. Study on NVOCs concentration characteristics by season, time and climatic factors: Focused on pinus densiflora forest in national center for forest therapy. J. People Plants Environ. 21(5):403-409. https:// doi.org/10.11628/ksppe.2018.21.5.403

Shin, C.S., P.S. Yeon, M.N. Jo, and J.Y. Kim. 2015. Effects of forest healing activity on women's menopausal symptoms and mental health recovery. J. People Plants Environ. 18(4):319-325. https://doi.org/10.11628/ksppe. 2015.18.4.319

Son, H.M. 2017. Understanding and application of qualitative content analysis. J. Korean Assoc. Qual. Res. 2:56-63. https://doi.org/10.48000/KAQRKR.2017.2.56

Sung, S.H., J.H. Park, Y.J. Lee, and C.H. Han. 2015. The analysis of research trends on forest therapy in the korean journal. Integr. Med. Res. 4(1):138. https://doi. org/10.1016/j.imr.2015.04.265

Tyrväinen, L., A. Ojala, K. Korpela, T. Lanki, Y. Tsunetsugu, and T. Kagawa. 2014. The influence of ur- 
ban green environments on stress relief measures: A field experiment. J. Environ. Psychol. 38(1):1-9. https:// doi.org/10.1016/j.jenvp.2013.12.005

Ulrich, R. 1984. View through a window may influence recovery from surgery. Science. 224(4647):420-421. https://doi.org/10.1126/science.6143402

Ulrich, R., R. Simons, B. Losito, E. Fiorito, M. Miles, and
M. Zelson. 1991. Stress recovery during exposure to natural and urban environments. J. Environ. Psychol. 11(3): 201-230. https://doi.org/10.1016/S0272-4944(05)80184-7

Yoo, R.H., M.A. Jeong, and K.H. Shin. 2015. A study on the activation of forest therapy by the trend analysis related to naturopathy. J. Korean Inst. For. Recreat. 19(2):43-51. https://doi.org/10.34272/forest.2015.19.2.005 